\title{
Avaliação da qualidade ambiental de corpos hídricos urbanos utilizando análise multivariada
}

\author{
Evaluation of environmental quality of urban water bodies using multivariate \\ analysis

\section{Evaluación de la calidad ambiental de cuerpos hídricos urbanos utilizando análisis multivariada}

\author{
César de Oliveira Ferreira Silva ${ }^{1}$ \\ Danielle Goveia ${ }^{2}$
}

\begin{abstract}
Recebido em 05/02/2018; revisado e aprovado em 05/04/2018; aceito em 13/04/2018
\end{abstract}
DOI: http://dx.doi.org/10.20435/inter.v0i0.1832

\begin{abstract}
Resumo: O presente trabalho avaliou a qualidade da água em corpos hídricos urbanos utilizando técnicas estatísticas multivariadas. Na cidade de Sorocaba, SP, Brasil, foram selecionados dez corpos hídricos, e foram quantificadas nove variáveis limnológicas. Os resultados indicaram impactos devido ao descarte irregular de resíduos sólidos e esgoto doméstico. Diante dos resultados, são apresentadas diretrizes de gestão ambiental.

Palavras-chave: recursos hídricos urbanos; qualidade de água; análise multivariada; gestão integrada; impactos ambientais.
\end{abstract}

Abstract: The present study evaluated the water quality in urban water bodies using multivariate statistical
techniques. In Sorocaba, São Paulo, ten water bodies were sampled and nine limnological variables were
quantified. Irregular disposal of domestic waste and sewage was identified as impacting. Environmental
management guidelines are presented.

Keywords: urban water resources; water quality; multivariate analysis; integrated management; environmental impacts.

Resumen: El presente trabajo evaluó la calidad del agua en cuerpos hídricos urbanos utilizando técnicas estadísticas multivariadas. En Sorocaba, SP, se muestreó agua de diez cuerpos hídricos y fueron cuantificados nueve variables limnológicas. Se identificó como impactantes el descarte irregular de residuos y alcantarillado domésticos. Se presentan directrices de gestión ambiental.

Palabras clave: recursos hídricos urbanos; calidad de agua; análisis multivariado; gestión integrada; impactos ambientales.

\section{INTRODUÇÃO}

De acordo com os censos demográficos realizados pelo Instituto Brasileiro de Geografia e Estatística (IBGE, s.d.), em 1940 a população do campo era de 68,8\% e, em 2014, apresenta um quadro oposto, com $85,2 \%$, da população concentrada em áreas urbanas. A urbanização gera impactos ao ambiente, por potencializar a desigualdade social, por provocar carência de habitação, desemprego, problemas de higiene e de saneamento básico, e, em situações extremas, é capaz de tornar a paisagem urbana ambientalmente degradada nos meios físico, biótico e antrópico (GALFI et al., 2016; MEDEIROS et al., 2017).

Dentro desse contexto, Tucci (2008) indica que os corpos hídricos situados nessas regiões sofrem pressão continuamente por diversos fatores: ausência de coleta e/ou tratamento de resíduos sólidos e esgoto doméstico, impermeabilização, ocupação irregular e degradação ambiental das margens de corpos hídricos, problemas de drenagem urbana e ausência de planos integrados de gestão ambiental.

\footnotetext{
${ }^{1}$ Universidade Estadual Paulista "Júlio de Mesquita Filho" (UNESP), Botucatu, São Paulo, Brasil.

2 Universidade Estadual Paulista "Júlio de Mesquita Filho" (UNESP), Itapeva, São Paulo, Brasil.
} 
Há atualmente um crescente esforço para identificar e quantificar os impactos da interferência humana nos recursos hídricos. Indicadores de qualidade de água vêm sendo desenvolvidos como ferramenta para mensurar diferentes níveis de contaminação (FREMAUX et al., 2009; GUMBO; DZAGA; NETHENGWE, 2016). Os índices de qualidade de água apresentam a vantagem de facilitar a comunicação entre as agências reguladoras e a população. Entretanto não é possível verificar claramente qual é o parâmetro de maior impacto na classificação da qualidade da água, principalmente quando esse impacto já é fixado através do peso predefinido de cada variável, como no caso do Índice de Qualidade de Água (IQA) (COMPANHIA AMBIENTAL DO ESTADO DE SÃO PAULO [CETESB], 2016), o que dificulta a identificação e detecção da origem da contaminação, consequentemente impossibilitando ações remediadoras.

Conhecer a relação que os parâmetros apresentam entre si é uma alternativa para avaliar o impacto ambiental. Uma alternativa é usar ferramentas matemáticas, com a estatística descritiva, regressão linear e análise multivariada (mais especificamente a análise fatorial). Segundo Hair et al. (2005), a análise fatorial realiza uma redução de informação derivada de um número de variáveis originais em um conjunto menor de variáveis estatísticas (fatores) com perda mínima de informação. Possibilita, ainda, identificar as variáveis que são responsáveis pela dispersão das observações e evidenciar possíveis agrupamentos, de acordo com seu grau de similaridade ou dissimilaridade (ANDRADE et al., 2010; FERNANDES et al., 2010; SALGADO et al., 2011). Por meio da análise fatorial de componentes principais, determina-se quais são as características de maior participação no comportamento das variáveis quando atuam conjuntamente (por exemplo, qual das variáveis limnológicas medidas mais impacta na qualidade da água) e definir as características físico-químicas da água que deverão ser monitoradas com maior prioridade, reduzindo-se, assim, os custos com análises de características de menor importância na variabilidade da qualidade das águas (GOMES; CAVALCANTE, 2017).

A degradação de corpos hídricos devido à urbanização e industrialização tem sido estudada utilizando ferramentas estatísticas da análise multivariada em diversos países, como Brasil (DANIEL et al., 2002; SILVA et al., 2013; MEDEIROS et al., 2017), Colômbia (SANDOVAL et al. 2014), Estados Unidos da América (O’NEILL et al., 2013; GHOLIZADEH; MELESSE; REDDI, 2016), África do Sul (GUMBO; DZAGA; NETHENGWE, 2016), Portugal (GOMES et al., 2014), Índia (JABEEN et al., 2014), Turquia (BILGIN, 2015) e Suécia (GALFI et al., 2016).

O objetivo deste trabalho foi analisar e diagnosticar a qualidade da água de corpos hídricos urbanos do município de Sorocaba, Estado de São Paulo (SP), através de ferramentas de análise estatística multivariada, a saber: correlação multivariada, para verificar como os parâmetros se correlacionam, e análise de componentes principais (PCA), para verificar como as variações dos parâmetros de qualidade de água interagem, a fim de subsidiar diretrizes para tomada de decisão em gestão ambiental.

\section{METODOLOGIA}

\section{1 Área de estudo}

A cidade de Sorocaba, localizada no estado de São Paulo, vem passando por um processo de urbanização nas duas últimas décadas, preparando-se para uma previsível expansão. Apresenta atualmente 659.871 habitantes, densidade demográfica de $1.465,14$ hab. $/ \mathrm{km}^{2}$ e a 10 o maior densidade de veículos automobilísticos (1,46 habitante por veículo ou aproximadamente três veículos para cada dois habitantes) do Brasil (IBGE, s.d.). 
O município apresenta muitos corpos hídricos localizados em parques localizados na extensão urbana, e o Rio Sorocaba, que corta grande parte urbana do município. Amostras de água foram coletadas em outubro de 2015 em dez pontos da zona urbana de Sorocaba, como exibido na Figura 1, que não pontua a localização do condomínio por confidencialidade. O único ponto onde amostras foram coletadas em corpo hídrico lótico foi o Rio Sorocaba (SOR), que é o principal rio do município, enquanto todos os outros compreenderam lagos urbanos, corpos hídricos lênticos. Os pontos de coleta apresentam em seu entorno áreas urbanizadas, degradadas e compostas por vegetação ornamental, como gramados e árvores de pequeno porte, são eles: os lagos dos Parques das Águas "Maria Barbosa da Silva" (PA), Parque Campolim (CAM), da Água Vermelha (PAV), Parque Kassatu Maru (PKM), do Jardim Botânico (JB) e de um Condomínio particular (CON), da Prefeitura de Sorocaba (PRE) do Zoológico Quinzinho de Barros (ZOO) e do Parque Natural "Chico Mendes" (PNC).

A definição da qualidade da água, como estipulada pelos padrões de qualidade na Resolução 357 do Conselho Nacional do Meio Ambiente (CONAMA) de 2005 e suas modificações nas resoluções 410 de 2009 e 430 de 2011, faz referência ao tipo de uso ao qual se destina. Os parâmetros são definidos em limites aceitáveis das substâncias presentes de acordo com o uso da água referente à classe à qual o corpo hídrico se enquadra, na qual os aqui estudados se enquadram nas classes 1 (ponto SOR), 3 (ZOO, JB e PNC) e 4 (PA, CAM, PAV, PRE, CON e PKM).

Figura 1 - Localização dos pontos de amostragem em corpos hídricos urbanos (indicados por suas siglas) no município de Sorocaba, SP

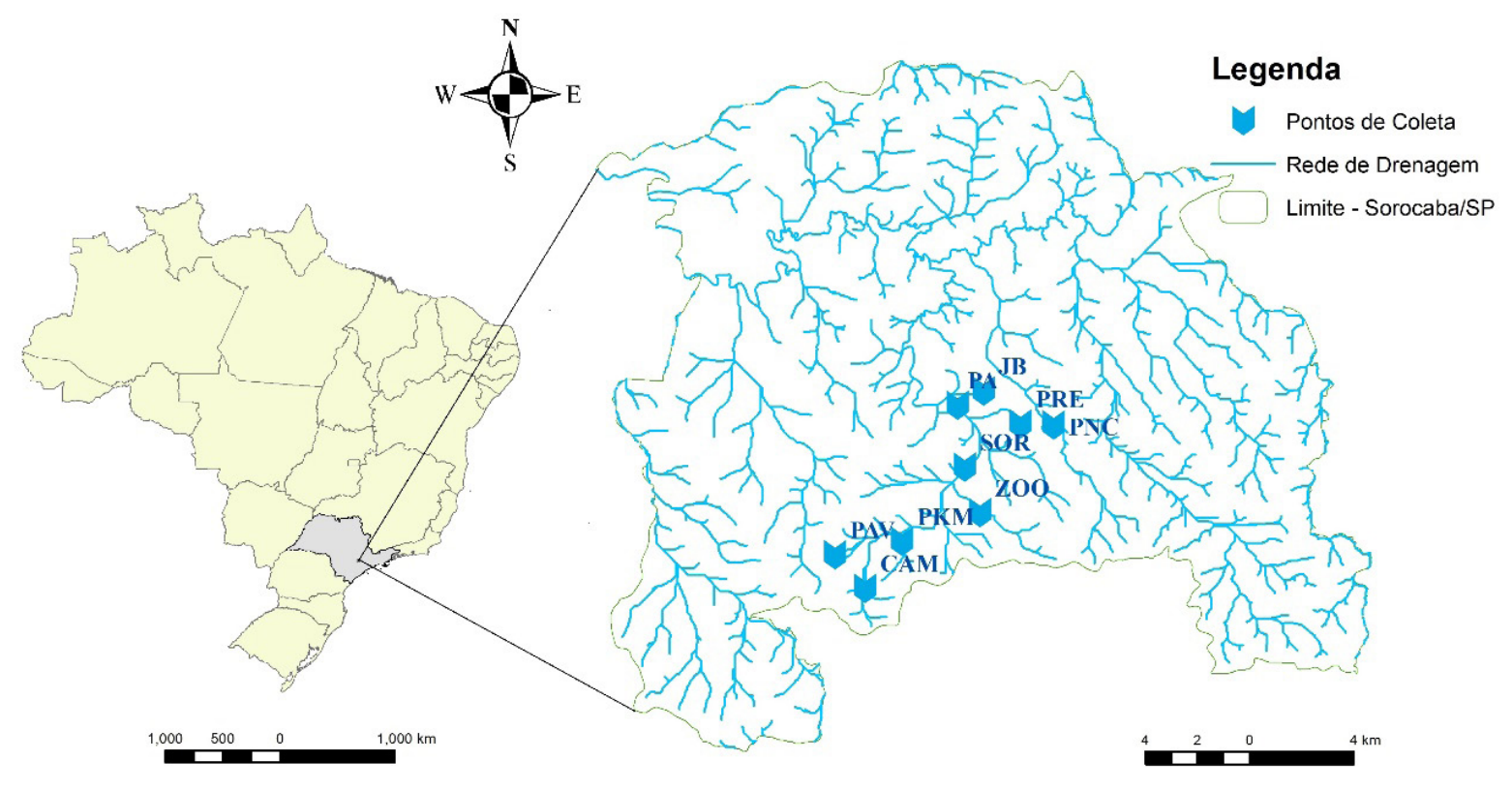

Fonte: Elaborado pelos autores, utilizando arquivos vetoriais do IBGE com software ArcGIS 10.4

De acordo com a classificação climática de Köppen, o clima de Sorocaba, SP, é subtropical úmido com inverno seco e verão quente. A temperatura média anual é de $22^{\circ} \mathrm{C}$ com máxima média de $25^{\circ} \mathrm{C}$ e mínima de $18^{\circ} \mathrm{C}$. A precipitação média anual é de $1311 \mathrm{~mm}$, sendo janeiro o mês mais chuvoso (237 mm) e agosto o mais seco (33 mm) (CEPAGRI, s.d.). 


\subsection{Amostragem e análise química de água}

Cinco amostras foram coletadas em superfície, acerca de $30 \mathrm{~cm}$ de profundidade, no mês de outubro de 2015. A medição do pH e oxigênio dissolvido (OD) foram realizadas com pHmêtro KEDID (modelo CT 6021) e Oxímetro Digimed $®$ (modelo MP-4P), respectivamente. Também foram medidas a demanda bioquímica de oxigênio (diferença entre o índice de OD da amostra logo em seguida à coleta à $20^{\circ} \mathrm{C}$ e após 5 dias também à $20^{\circ} \mathrm{C}$ ) e turbidez (turbidímetro QUIMIS ${ }^{\circledR}$, modelo Q279P com comprimento de onda de 450nm). O resíduo total foi obtido por gravimetria. A medição do fósforo total, nitrogênio total e clorofila-a foi realizada com espectrofotômetro ( $\mathrm{HACH}{ }^{\circledR}$, modelo 3OR3900). A análise microbiana consistiu na amostragem em frasco tipo SCHOOT® com tampa autoclavado e a contagem de coliformes termotolerantes (NIEMELA; LEE; FRICKER, 2003; BUCKALEW et al., 2006; FREMAUX et al., 2009), utilizando o método dos tubos múltiplos seguindo a norma L5.202 (CETESB, 2018). Esses parâmetros foram escolhidos por serem os componentes do Índice de Qualidade de Água (IQA) e Índice de Estado Trófico (IET), adotados pelo Estado de São Paulo (CETESB, 2016).

\subsection{Análise estatística}

Estatística descritiva e correlações de Spearman (com variação estatisticamente significativa, ou seja, $p<0,05$ ) dos indicadores limnológicos foram realizadas para avaliar as tendências, variabilidade e relacionamentos entre as variáveis (BILGIN, 2015; HARTMANN et al., 2016; KIKUCHI et al., 2017). Análise de componentes principais (PCA) exploratória foi utilizada para entender a contribuição de cada parâmetro de qualidade de água para a variabilidade observada (DALAL et al., 2010; LEGENDRE; LEGENDRE, 2012; JABEEN et al., 2014; WALKER et al., 2015; GUMBO; DZAGA; NETHENGWE, 2016).

O teste de Kaiser-Meyer-Olkin (KMO), ou índice de adequação da amostra, foi empregado para avaliar a pertinência das amostras para a PCA (KAISER, 1974). Esse teste analisa a redundância das variáveis pela análise de correlação parcial, não sendo apropriado aplicar análise fatorial quando a correlação entre as variáveis é próxima a zero. Sendo o valor retornado pelo teste entre 0 e 1, valores maiores que 0,6 indicam que as variáveis e amostras são pertinentes para análises fatoriais (MAO; MO; GUO, 2013; GUMBO; DZAGA; NETHENGWE, 2016; GHOLIZADEH; MELESSE; REDDI, 2016). Também foi necessário padronizar os dados antes da aplicação da PCA, pelas suas diferenças dimensionais, utilizando a função de padronização pelo z-score (LIU; LIN; KUO, 2003). As análises estatísticas foram realizadas com o software R (R CORE TEAM, s.d.).

\section{RESULTADOS E DISCUSSÃO}

\subsection{Determinação dos parâmetros de qualidade de água}

A Tabela 1 apresenta os valores médios (e desvio padrão) dos parâmetros de qualidade de água. Os coliformes termotolerantes apresentam-se elevados em todas as situações. O pH excede a faixa de 6 a 9 somente no ponto PA (9.70 \pm 0.90). Quanto à $\mathrm{DBO}_{5}$, o Rio Sorocaba apresenta valor inadequado para um corpo hídrico de classe $1,6.10 \mathrm{mg} \mathrm{L}^{-1} \pm 0.55$ (que deveria ser menor ou igual a $3 \mathrm{mg} \mathrm{L}^{-1}$ ), os lagos de parques que devem ter condições de oxigênio para fauna aquática (como Zoológico e Chico Mendes) têm índices favoráveis ( $0.70 \pm 0.25$ e $0.30 \pm 0.10$, res- 
pectivamente) e os demais apresentam valores de $\mathrm{DBO}_{5}$ dentro do valor permitido para a classe 4 (que pode exceder $10 \mathrm{mg} \mathrm{L}^{-1}$ ). O resíduo total apresentou-se excessivamente alto nos pontos do Parque das Águas e no Condomínio (850.00 0.45 e $960.00 \pm 0.35$, respectivamente), sendo que a legislação estabelece que resíduos devem ser "virtualmente ausentes" (BRASIL, 2005, Art. 16, l, f). O nitrogênio e fósforo totais e clorofila-a, todos parâmetros indicadores de eutrofização, apresentam valores altos no Zoológico, Parque das Águas e Parque Kassatu Maru. Nos demais corpos hídricos, as anomalias se apresentam de forma mais difusa entre esses três indicadores.

3.2 Avaliação estatística dos parâmetros de qualidade de água

A Tabela 2 apresenta as correlações entre os indicadores limnológicos estudados, onde se verificou que os coliformes termotolerantes apresentam correlação positiva com o fósforo total $(r=0.97)$ e clorofila-a $(r=0.59)$, indicando que a eutrofização dos corpos hídricos é acompanhada com o aumento de coliformes. O oxigênio dissolvido decresce com a presença de coliformes termotolerantes $(r=-0.53)$, fósforo total $(r=-0.55)$ e moderadamente com a turbidez $(r=-0.21)$, indicando que visualmente uma maior turbidez e deposição de nutrientes nos corpos hídricos resulte em menor disponibilidade de oxigênio na água. O nitrogênio total tem impacto negativo na $\mathrm{DBO}_{5}(r=-0.52)$. O pH cresce acompanhando a turbidez $(r=-0.75)$. Como a clorofila-a decresce moderadamente com o resíduo total $(r=-0.27)$, entende-se que o material residual é, em sua maioria, mineral ou artificial e não vegetal.

$\mathrm{O}$ teste $\mathrm{KMO}$ resultou no coeficiente 0.74 , demonstrando que os dados amostrais de qualidade de água, caso não haja redundâncias, podem ser estudados com análise fatorial (MAO; MO; GUO, 2013; GUMBO; DZAGA; NETHENGWE, 2016; MEDEIROS et al., 2017).

A aplicação da PCA para os indicadores de qualidade de água gerou cinco componentes principais com autovalores maiores que a unidade, que explicam $78,5 \%$ da variância do conjunto de dados. Não há consenso sobre o número de fatores que devem ser utilizados na análise, o critério de Kaiser sugere o uso dos fatores com autovalor acima de um (KAISER, 1974), enquanto Hair et al. (2005) sugerem que o número de componentes que representem $60 \%$ da variância acumulada, refletem uma ideia aceitável da variância original. No presente caso, ambos os critérios sugeridos são utilizados. Acompanhando Liu, Lin e Kuo (2003), Guedes et al. (2012), Rocha e Costa (2015) e Medeiros et al. (2017), considerou-se que uma variável é fortemente associada a um componente quando tem uma carga maior que 0,7 e razoavelmente associada com carga maior que 0,5 , com isso, como é possível verificar na Tabela 3, apenas os dois primeiros componentes apresentam fortes associações, havendo associações moderadas no terceiro componente, sendo assim, apenas esses componentes foram apresentados na Tabela 3 e postos em discussão.

O primeiro componente (33,4\% da variância total) foi associado fortemente com $\mathrm{pH}$ e turbidez, indicando que essas variáveis são as mais significativas na definição da qualidade da água, e associado moderadamente aos coliformes termotolerantes e resíduo total (SILVA et al., 2013; JABEEN et al., 2014; GUMBO; DZAGA; NETHENGWE, 2016; MEDEIROS et al., 2017). O segundo componente $(32,5 \%)$ foi fortemente associado à $\mathrm{DBO}_{5}$, fósforo e oxigênio dissolvido, e moderadamente com clorofila-a e nitrogênio, e pode ser interpretado como a influência de fontes de poluição que depositam nutrientes nos corpos hídricos e geram eutrofização (JABEEN et al., 2014; MEDEIROS et al., 2017). Aumento na $\mathrm{DBO}_{5}$ é provocado por despejos de origem predominantemente orgânica, induzindo ao completo esgotamento do oxigênio na água, provocando o desaparecimento de peixes e outras formas de vida aquática, assim como um aumento da microflora, que interfere no equilíbrio da vida aquática (CETESB, 2016). 


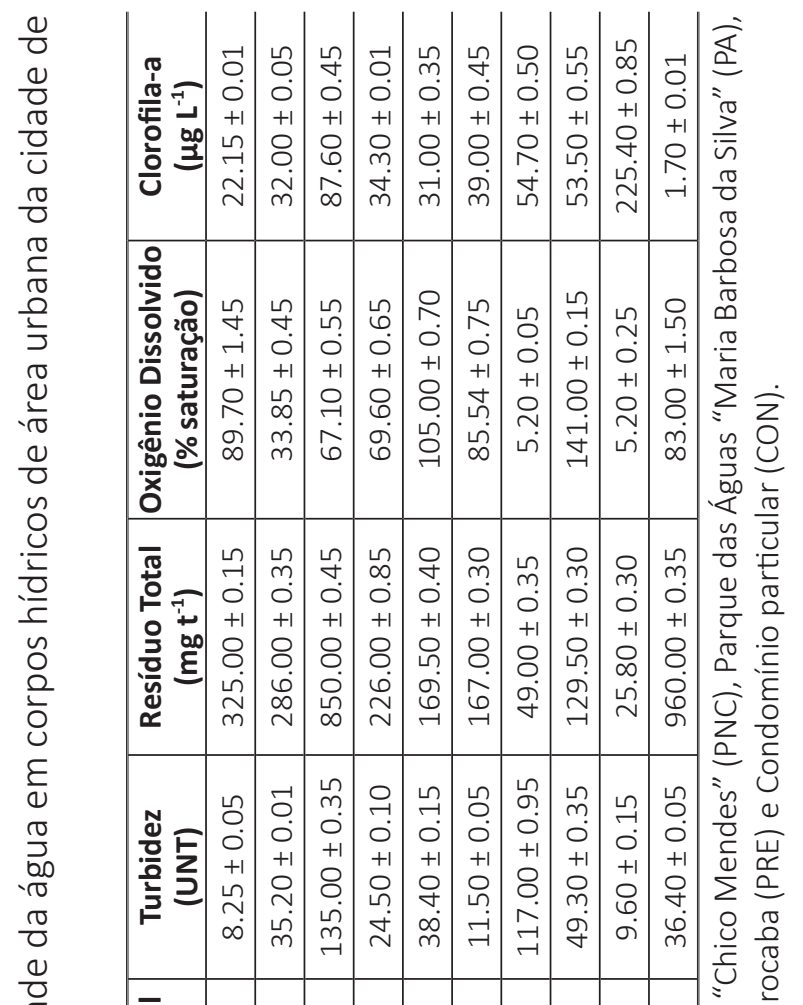

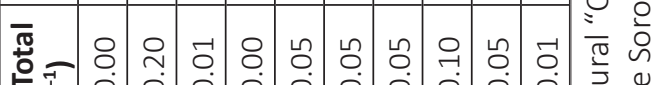

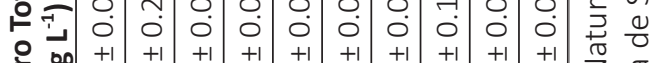

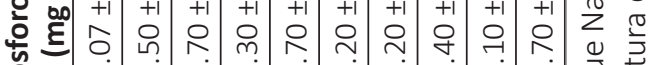

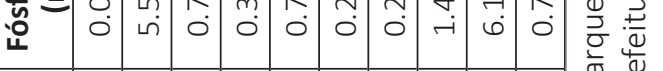
ब 늠 号

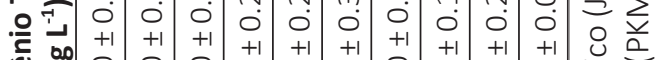

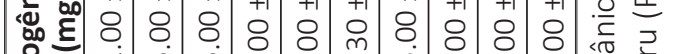
蒙 in

응

兽

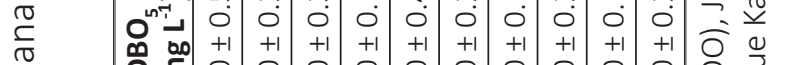

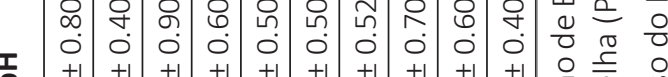
일

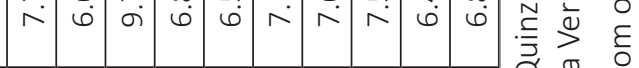
-

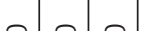


Tabela 3 - Componentes principais e cargas de cada parâmetro limnológico amostrado em corpos hídricos de Sorocaba, SP, em outubro de 2015

\begin{tabular}{l|c|c|c}
\hline \multirow{2}{*}{} & \multicolumn{3}{|c}{ Carga Fatorial } \\
\cline { 2 - 4 } & $\begin{array}{c}\text { Primeiro } \\
\text { Componente }\end{array}$ & $\begin{array}{c}\text { Segundo } \\
\text { Componente }\end{array}$ & $\begin{array}{c}\text { Terceiro } \\
\text { Componente }\end{array}$ \\
\hline Coliformes Termotolerantes & 0,6848 & 0,2253 & $-0,5151$ \\
\hline $\mathrm{pH}$ & $\mathbf{- 0 , 9 1 9 6}$ & 0,0467 & 0,2941 \\
\hline $\mathrm{DBO}_{5}$ & 0,3077 & $\mathbf{- 0 , 8 2 4 5}$ & 0,2740 \\
\hline Nitrogênio & $-0,4557$ & 0,6138 & $-0,2087$ \\
\hline Fósforo & 0,4699 & $\mathbf{0 , 7 3 9 0}$ & 0,0767 \\
\hline Turbidez & $\mathbf{- 0 , 7 9 3 1}$ & 0,3102 & 0,1434 \\
\hline Resíduo Total & $-0,6587$ & $-0,0065$ & $-0,4293$ \\
\hline OD & $-0,1537$ & $\mathbf{- 0 , 8 9 3 1}$ & 0,0177 \\
\hline Clorofila & 0,2926 & 0,6126 & 0,4999 \\
\hline Proporção da Variância & 0,3344 & 0,325 & 0,1264 \\
\hline Variância Acumulada & 0,3344 & 0,6594 & 0,7858 \\
\hline
\end{tabular}

Fonte: Dados da pesquisa, processados com o uso do R 3.4.

A clorofila-a e fósforo são indicadores de eutrofização, e sua variação está relacionada a descarte irregular de esgoto doméstico, que gera aporte de nutrientes que aumentam a microfauna na superfície do corpo hídricos e impedem a circulação de oxigênio e luz (O'NEILL et al., 2013; CETESB, 2016).

O terceiro componente $(12,6 \%)$ foi associado moderadamente aos coliformes termotolerantes, indicando a influência de fatores biológicos devido às descargas clandestinas de esgotos (O’NEILL et al., 2013; CETESB, 2016).

O comportamento das variáveis e sua distribuição nos componentes permitem estabelecer relações que estas apresentam entre si, assim como feito por outros autores (ANDRADE et al., 2010; GUEDES et al., 2013; SILVA et al., 2013; GHOLIZADEH; MELESSE; REDDI, 2016; MEDEIROS et al., 2017).

Ao se considerar que o primeiro componente, que foi o que mais explicou as variâncias totais dos dados, é resultante do transporte e lixiviação de materiais alóctones, que aumentam a deposição de sedimentos (resíduos totais) e alteram pH e turbidez (GHOLIZADEH; MELESSE; REDDI, 2016; HARTMANN et al., 2016), deduz-se que o uso e a ocupação irregular do solo no entorno dos corpos hídricos estudados, que se encontravam degradados, já que apresentavam solo exposto e ausência de vegetação nativa, influenciaram diretamente a qualidade da água.

Foi verificada uma grande dispersão entre os indicadores (Figura 2), pois, de acordo com a interpretação visual da representação bidimensional dos dois primeiros componentes principais, adotada por Medeiros et al. (2017), os indicadores cujo segmento de reta formam menores ângulos em relação aos eixos do plano cartesiano produzem melhor diferenciação entre os pontos amostrais ( $\mathrm{pH}, \mathrm{OD}$ e resíduo total), enquanto os parâmetros que formam ângulos próximos a $45^{\circ}$ (fósforo total, nitrogênio e clorofila-a) tornam a variação mais difusa, fazendo com que a análise direta de seus valores sejam pouco distinguíveis, tornando aconselhável o uso de análise fatorial e componentes principais, já que sua redução de parâmetros torna essa variação melhor distinguível (HAIR et al., 2005; GHOLIZADEH; MELESSE; REDDI, 2016; MEDEIROS et al., 2017). 
Figura 2 - Representação bidimensional dos componentes principais de indicadores de qualidade de água em corpos hídricos de Sorocaba, SP

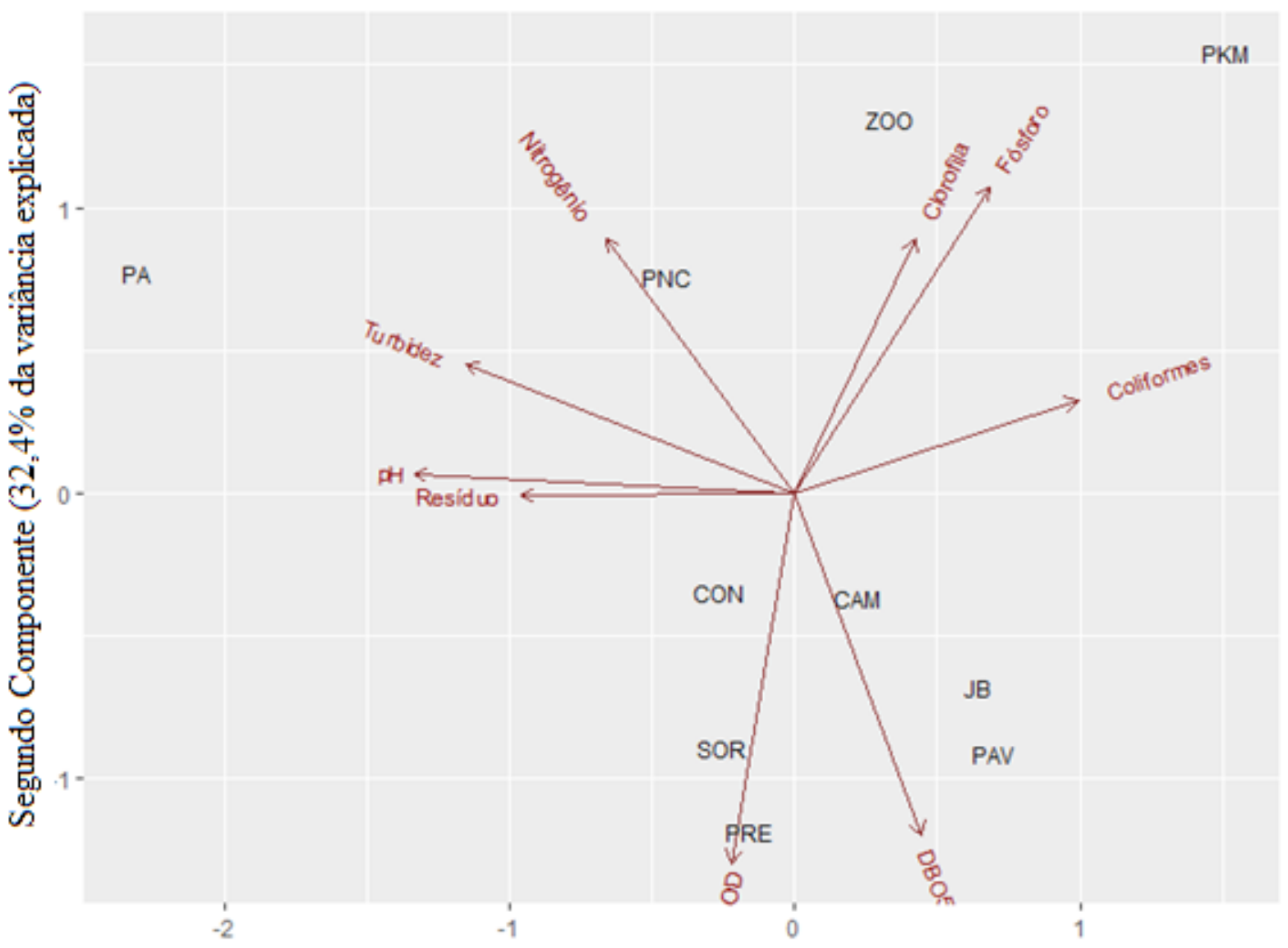

\section{Primeiro Componente (33,4\% da variância explicada)}

Fonte: Dados da pesquisa, processados com o uso do R 3.4.

\subsection{Diagnóstico de impactos ambientais e diretrizes de gestão ambiental}

Com a identificação dos principais impactos ambientais e indicadores de qualidade de água de maior influência em seu monitoramento, foi possível definir diretrizes para as intervenções necessárias à restituição da qualidade ambiental dos corpos hídricos. Vale notar que a PCA permitiu agrupar os parâmetros e relacioná-los com seus principais impactos ambientais.

Sugere-se que sejam priorizados o monitoramento dos parâmetros que compõem o primeiro componente principal, $\mathrm{pH}$, turbidez, coliformes termotolerantes e resíduo total, por serem detectados como os principais influenciadores estatísticos na variação do comportamento da qualidade da água (LIU; LIN; KUO, 2003), sendo necessários ações que englobem o tratamento da água e monitoramento de qualidade e fiscalização contra descarte clandestino de resíduos domésticos e esgoto (MEDEIROS et al., 2017), sendo também necessário avaliar as condições de preservação nas margens dos corpos hídricos, pelo fato de a erosão impactar na deposição de resíduos e sedimentos (HATT et al., 2004). 


\section{CONCLUSÕES}

A vulnerabilidade e degradação dos recursos hídricos do município de Sorocaba, SP, provocada por descartes irregulares de resíduos, promovem perda de qualidade ambiental nas águas urbanas, somada à falta e/ou ineficácia da fiscalização ambiental contra atividades clandestinas.

A Análise de Componentes Principais (PCA) permitiu a seleção de três componentes indicadores da qualidade das águas de corpos hídricos urbanos de Sorocaba, SP, explicando 87,40\% da variância total. A utilização de análises estatísticas multivariadas promoveu a comparação dos nove indicadores de qualidade de água de forma agregada, permitindo a verificação de correlações úteis para detecção dos problemas-chave para gestão de recursos hídricos integrados, no caso, houve evidências que indicaram que a principal fonte de poluição vem de resíduos sólidos domésticos (pelas alterações na turbidez, pH e resíduos totais) e, em menor escala, do descarte irregular de esgoto domésticos, que é um potencial causador de eutrofização por aporte de nutrientes.

Sugeriu-se, como diretrizes para melhora na qualidade ambiental dos recursos hídricos estudados, o tratamento da água e monitoramento de qualidade, fiscalização contra descarte clandestino de resíduos domésticos e esgoto e restauração florestal das margens degradadas.

\section{AGRADECIMENTOS}

Agradecimentos à FUNDUNESP, CNPQ (458875/2014-7) e FAPESP (2016/23728-8) pelo auxílio financeiro.

\section{REFERÊNCIAS}

ANDRADE, E. M.; LOPES, F. B.; PALÁCIO, H. A. Q.; NASCIMENTO, D.; ALEXANDRE, D. M. B. Land use and groundwater quality: The case of Baixo Acaraú Irrigated Perimeter, Brazil. Revista Ciência Agronômica, Fortaleza, v. 41, n. 2, p. 208-15, abr./jun. 2010.

BILGIN, A. An assessment of water quality in the Coruh Basin (Turkey) using multivariate statistical techniques. Environmental Monitoring and Assessment, v. 187, n. 11, p. 721, nov. 2015.

BRASIL. Resolução CONAMA n. 357, de 17 de março de 2005. Classificação de águas, doces, salobras e salinas do Território Nacional. Diário Oficial da União, n. 053, de 18/03/2005.

BUCKALEW, D. W.; HARTMAN, L. J.; GRIMSLEY, G. A.; MARTIN, A. E.; REGISTER, K. M. A long-term study comparing membrane filtration with Colilert defined substrates in detecting fecal coliforms and Escherichia coli in natural waters. Journal of Environmental Management, v. 80, n. 3, p. 191-97, set. 2006.

CEPAGRI. Clima dos Municipios Paulistas. [s.d.]. Disponível em: http://www.cpa.unicamp.br/outrasinformacoes/clima_muni_584.html. Acesso em: 26 mar. 2018.

COMPANHIA AMBIENTAL DO ESTADO DE SÃO PAULO (CETESB). L5.202: Coliformes totais, coliformes termotolerantes e Escherichia coli-Determinação pela técnica de tubos múltiplos. São Paulo: CETESB, 2018.

COMPANHIA AMBIENTAL DO ESTADO DE SÃO PAULO (CETESB). Qualidade das águas interiores no estado de São Paulo. São Paulo: CETESB, 2016.

DALAL, S. G.; SHIRODKAR, P. V.; JAGTAP, T. G.; NAIK, B. G.; RAO, G. S.; Evaluation of significant sources influencing the variation of water quality of Kandla creek, Gulf of Katchchh, using PCA. Environmental Monitoring and Assessment, v. 163, n. 2, p. 49-56, abr. 2010. 
DANIEL, M. H. B.; MONTEBELO, A. A.; BERNARDES, M. C.; OMETTO, J. P. H. B.; CAMARGO, P. B.; KRUSCHE, A. V.; BALLESTER, M. V.; VICTORIA, R. L.; MARTINELLI, L. A. Effects of urban sewage on dissolved oxygen, dissolved inorganic and organic carbon, and electrical conductivity of small streams along a gradient of urbanization in the Piracicaba river basin. Water, Air, and Soil Pollution, v. 136, n. 1-4, p. 189-206, maio 2002.

FERNANDES, F. B. P.; ANDRADE, E. M.; FONTENELE, S. B.; MEIRELES, A. C. M.; RIBEIRO, J. A. Análise de agrupamento como suporte à gestão qualitativa da água subterrânea no semiárido cearense. Revista Agro@mbiente On-line, Boa Vista, RR, v. 4, n. 2, p. 86-95, jul./dez. 2010.

FREMAUX, B.; BOA, T.; CHAYKOWSKI, A.; KASICHAYANULA, S.; GRITZFELD, J.; BRAUL, L. Assessment of the microbial quality of irrigation water in a prairie watershed. Journal of Applied Microbiology, v. 106, n. 2, p.442-54, mar. 2009.

GALFI, H. O.; STERLUND, H.; MARSALEK, J.; VIKLANDER, M. Indicator bacteria and associated water quality constituents in stormwater and snowmelt from four urban catchments. Journal of Hydrology, v. 539, n. 1, p. 125-40, ago. 2016.

GHOLIZADEH, M. H.; MELESSE, A. M.; REDDI, L. Water quality assessment and apportionment of pollution sources using APCS-MLR and PMF receptor modeling techniques in three major rivers of South Florida. Science Total Environment, v. 566, p. 1552-67, jun. 2016.

GOMES, A. I.; PIRES, J. C. M.; FIGUEIREDO, S. A.; BOAVENTURA, R. A. R. Optimization of river water quality surveys by multivariate analysis of physicochemical, bacteriological and ecotoxicological data. Water Resources Management, v. 28, n. 5, p. 1345-61, maio 2014.

GOMES, M. C. R.; CAVALCANTE, I. N. Aplicação da análise estatística multivariada no estudo da qualidade da água subterrânea. Águas Subterrâneas, São Paulo, v. 31, n. 1, p. 134-49, jan. 2017.

GUEDES, H. A. S.; SILVA, D. D.; ELESBON, A. A. A.; RIBEIRO, C. B. M.; MATOS, A. T. Aplicação da análise estatística multivariada no estudo da qualidade da água do Rio Pomba, MG. Revista Brasileira de Engenharia Agrícola e Ambiental, Campina Grande, PB, v. 16, n. 5, p. 558-63, 2012.

GUMBO, J. R.; DZAGA, R. A.; NETHENGWE, N. S. Impact on water quality of Nandoni water reservoir downstream of municipal sewage plants in Vhembe District, South Africa. Sustainability, v. 8, n. 7, p. 597, jun. 2016.

HAIR, J. F.; ANDERSON, R. E.; TATHAN, R. L.; BLACK, W. C. Multivariate data analysis. New Jersey: Prentice Hall, 2005.

HARTMANN, H.; SNOW, J. A.; SU, B.; JIANG, T. Seasonal predictions of precipitation in the Aksu-Tarim River basin for improved water resources management. Global Planet Change, v. 147, n. 1, p. 86-96, dez. 2016.

HATT, B. E.; FLETCHER, T. D.; WALSH, C. J.; TAYLOR, S. L. The influence of urban density and drainage infrastructure on the concentrations and loads of pollutants in small streams. Environmental Management, v. 34, n. 1, p. 112-24, jul. 2004.

INSTITUTO BRASILEIRO DE GEOGRAFIA E ESTATÍ́STICA - IBGE. Instituto Brasileiro de Geografia e Estatística. [s.d.]. Disponível em: https://www.ibge.gov.br/. Acesso em: 12 fev. 2018.

JABEEN, S.; SHAH, M. T.; AHMEDC, I.; KHAND, S.; HAYAT, M. Q. Physicochemical parameters of surface and ground water and their environmental impact assessment in the Haripur Basin, Pakistan. Journal of Geochemical Exploration, v. 139, n. 1, p. 1-7, jan. 2014. 
KAISER, H. F. An index of factorial simplicity. Psychometrika, v. 69, n. 1, p 31-6, mar. 1974.

KIKUCHI, T.; FUJII, M.; TERAO, K.; JIWEI, R.; LEE, Y. P.; YOSHIMURA, C. Correlations between aromaticity of dissolved organic matter and trace metal concentrations in natural and effluent waters: a case study in the Sagami River Basin, Japan. The Science of the Total Environment, v. 576, n. 1, p. 36-45, jan. 2017.

LEGENDRE P.; LEGENDRE L. Numerical ecology. Amsterdã: Elsevier, 2012.

LIU, C. W.; LIN, K. H.; KUO, Y. M. Application of factor analysis in the assessment of groundwater quality in a blackfoot disease area in Taiwan. The Science of the Total Environment, v. 313, n. 1-3, p. 77-89, set. 2003.

MAO, L.; MO, D.; GUO, Y. Multivariate analysis of heavy metals in surface sediments from lower reaches of the Xiangjiang River, southern China. Environment Earth Science, v. 69, n. 3, p. 765-71, jun. 2013.

MEDEIROS, G. A.; TRESMONDI, A. C. C. L.; QUEIROZ, B. P. V.; FENGLER, F. H.; ROSA, A. H.; FIALHO, J. M.; LOPES, R. S.; NEGRO, C. V.; SANTOS, L. F.; RIBEIRO, A. I. Water quality, pollutant loads, and multivariate analysis of the effects of sewage discharges into urban streams of Southeast Brazil. Energy, Ecology and Environment, v. 2, n. 4, p. 259-76, 2017.

NIEMELA, S. I,; LEE, J. V.; FRICKER, C. R. A comparison of the International Standards Organisation reference method for the detection of coliforms and Escherichia coli in water with a defined substrate procedure. Journal of Applied Microbiology, v. 95, n. 1, p. 1285-92, out. 2003.

O'NEILL, S.; ADHIKARI, A. R.; MAHESH, R.; GAUTAM, M. R.; ACHARYA, K. Bacterial contamination due to point and nonpoint source pollution in a rapidly growing urban center in an arid region. Urban Water Journal, v. 10, n. 6, p. 411-21, fev. 2013.

R CORE TEAM. R: A language and environment for statistical computing. [s.d.]. Disponível em: https:// www.R-project.org/. Acesso em: 26 mar. 2018.

ROCHA, C. H. B.; COSTA, H. F. Variação temporal de parâmetros limnológicos em manancial de abastecimento em Juiz de Fora, MG. Revista Brasileira de Recursos Hídricos, Porto Alegre, v. 20, n. 2, p. 543-50, abr./jun. 2015.

SALGADO, E. V.; ANDRADE, E. M.; FONTENELE, S. B.; MEIRELES, A. C. M. Similaridade das variáveis hidroquímicas com o uso da análise multivariada, na Bacia do Salgado, Ceará. Revista Caatinga, Mossoró, RN, v. 24, n. 3, p. 158-66, jul./set. 2011.

SANDOVAL, S.; TORRES, A.; DUARTE, M.; VELASCO, A. Assessment of rainfall influence over water quality effluent of an urban catchment: a data driven approach. Urban Water Journal, v. 11, n. 2, p. 116-26, abr. 2014.

SILVA, A. M.; SANTOS, A. R.; FERNANDES, R. A.; URBAN, R. C.; CARVALHO, R. M.; MANFRÉ, L. A.; DURRANT, S. F. Hydrosedimentological disequilibrium in a small, urbanized watershed. Acta Limnologica Brasiliensia, Rio Claro, SP, v. 25, n. 2, p. 140-9, abr./jun. 2013.

TUCCI, C. Águas urbanas. Estudos Avançados, São Paulo, v. 22, n. 63, p. 97-112, 2008.

WALKER, D.; JAKOVLJEVIC, D.; SAVIC, D.; RADOVANOVIC, M. Multi-criterion water quality analysis of the Danube River in Serbia: a visualisation approach. Water Research, v. 79, n. 1, p. 158-72, ago. 2015. 


\section{Sobre os autores:}

César de Oliveira Ferreira Silva - Mestre em Irrigação e Drenagem pelo Programa de Pós-Graduação em Agronomia (Irrigação e Drenagem) da Faculdade de Ciências Agronômicas da Universidade Estadual Paulista "Julio de Mesquita Filho" (UNESP). Engenheiro Ambiental pela UNESP. E-mail: cesaroliveira.f.silva@gmail.com, Orcid: http://orcid.org/0000-0002-5152-6497

Danielle Goveia - Pós-doutora em Química. Doutora e mestre em Química Analítica pelo Instituto de Química da Universidade Estadual Paulista "Julio de Mesquita Filho" (UNESP). Licenciada em Química pela Universidade Estadual de Maringá. Professora assistente doutora junto à Coordenadoria de Curso da Engenharia de Produção do Campus de Itapeva e credenciada no Programa de Pós-graduação em Engenharia de Biomateriais e Bioprocessos, da Faculdade de Ciências Farmacêuticas da UNESP. E-mail: danielle.goveia@unesp.br, Orcid: http://orcid.org/0000-0001-6170-5459 